\title{
METefnet: developments in metrology for moisture in materials
}

\author{
Stephanie Bell ${ }^{1, a}$, Rudolf Aro $^{2}$, Fausto Arpino ${ }^{3}$, Seda Aytekin ${ }^{4}$, Gino Cortellessa ${ }^{3}$, Marco Dell'Isola ${ }^{3}$, Zuzana Ferenčíková ${ }^{5}$, \\ Vito Fernicola ${ }^{6}$, Roberto Gavioso ${ }^{6}$, Eric Georgin ${ }^{7}$, Martti Heinonen ${ }^{8}$, Domen Hudoklin ${ }^{9}$, Lauri Jalukse ${ }^{2}$, Nuray Karaböce ${ }^{4}$, \\ Ivo Leito $^{2}$, Anssi Mäkynen ${ }^{10}$, Peng Miao ${ }^{1}$, Jan Nielsen ${ }^{11}$, lleana Nicolescu ${ }^{12}$, Martina Rudolfová ${ }^{5}$, Maija Ojanen-Saloranta ${ }^{8}$, \\ Petri Österberg $^{10,13}$, Peter Østergaard ${ }^{11}$, Mihaela Rujan ${ }^{12}$, Michela Sega ${ }^{6}$, Radek Strnad ${ }^{5}$ and Tereza Vachova ${ }^{5}$ \\ ${ }^{1}$ National Physical Laboratory (NPL), Hampton Road, Teddington, UK \\ ${ }^{2}$ University of Tartu (UT), Institute of Chemistry, Ravila 14a, Tartu 50411, Estonia \\ ${ }^{3}$ University of Cassino and Southern Lazio (UNICLAM), Via Di Biasio 43 - 03043 Cassino, Italy \\ ${ }^{4}$ National Metrology Institute of Turkey (TÜBITAK UME), Gebze-Kocaeli, Turkey \\ ${ }^{5}$ Czech Metrology institute (CMI), Okružni 31, 63800 Brno, Czech Republic \\ ${ }^{6}$ Istituto Nazionale di Ricerca Metrologica (INRiM), Strada delle Cacce 91, 10135 Torino, Italy \\ ${ }^{7}$ CETIAT, BP 52042, VILLEURBANNE Cedex, FRANCE \\ ${ }^{8}$ Centre for Metrology MIKES, VTT Technical Research Centre of Finland Ltd, P.O. Box 1000, FI-02044 VTT, Finland \\ ${ }^{9}$ University of Ljubljana (UL), Laboratory of Metrology and Quality, Faculty of Electrical Engineering, Trzaska 25, 1000 Ljubljana, Slovenia \\ ${ }^{10}$ University of Oulu (UOULU), CEMIS-Oulu, P.O.Box 127, 87400 Kajaani, Finland \\ ${ }^{11}$ Danish Technological institute (DTI), Kongsvang Allé 29, 8000 Aarhus C, Denmark \\ ${ }^{12}$ National Institute of Metrology (INM), Sos. Vitan-Barzesti Steet No. 11, Sector 4, 042 122, Bucharest, Romania \\ ${ }^{13}$ Measurepolis Development Ltd, Kehräämöntie 7, 87400 Kajaani, Finland
}

\begin{abstract}
Résumé. Bien que les mesures de teneur en eau soient largement utilisées dans l'industrie, les considérations métrologiques quant à cette mesure ne sont pas complètement abouties de sorte à fournir des mesures fiables et traçables au SI. Afin de remédier à ceci, le projet de recherche conjoint, Joint Research Project SIB64 "METefnet Metrology for moisture in materials", est actuellement en cours, et contribue au programme européen de recherche en métrologie European Metrology Research Programme. Le projet METefnet a pour objectifs de développer et d'améliorer l'approche métrologique de ce sujet. Ceci inclus notamment: le travail sur de nouvelles méthodes de référence pour évaluer la fraction massique en eau, l'amélioration des mesures mettant en œuvre la méthode primaire de type titration Karl Fischer, le développement de nouveaux matériaux de référence certifiés présentant une très bonne stabilité et permettant une traçabilité au SI, le développement de nouveaux étalons de transfert, la réalisation d'études visant à quantifier et réduire les effets liés à la prise d'échantillon, son transport et sa manipulation, le développement d'une nouvelle méthode pour étalonner les instruments mesurant l'humidité de surface, et l'amélioration des méthodes d'estimation d'incertitudes de ces mesures. Ce travail, réalisé dans le domaine de la métrologie de l'humidité au sein des matériaux, couvre à la fois le mesurande décrit comme étant spécifiquement la teneur en eau, seule, dans les matériaux, mais également un mesurande plus large pouvant inclure l'eau ainsi que d'autres liquides ou composés organiques volatiles; ceci afin de bien mettre en exergue la différence qui peut être observée entre ces deux mesurandes. Le projet global a pour objectif de soutenir une action de dissémination et de traçabilité au système SI des mesures de teneur en eau dans les matériaux avec une exactitude optimale et de développer une infrastructure métrologique cohérente pour ce type de mesures. Le travail technique ainsi que les dernières avancées vous sont ainsi présentées.
\end{abstract}

\section{Introduction}

Moisture content of materials is important in a vast range of applications. The presence of water influences active ingredients in pharmaceuticals, carbon-fibre composites, polymers, food powders, biomass, novel cellulose-based active paper, and many others - during processing, storage and use. In industrial processes, errors and inconsistencies in moisture measurement and control lead to decreased process speed and throughput, increased wastage, increased energy consumption in drying, and increased environmental emissions.

Reliable measurement of moisture in materials poses various challenges. Measurement methods for moisture are diverse, and they vary in what is measured; sometimes water content alone, but sometimes content of water and other liquid or volatile contents, so that the measurand is often operationally-defined. This can lead to risk of ambiguity.

\footnotetext{
${ }^{a}$ Corresponding author: stephanie.bell@npl.co.uk
} 
There are numerous published standard reference methods for moisture, particularly for mass loss on drying. These standard protocols differ for each material, because the results are method-dependent. It is desirable to reduce reliance on published methods, and to move further towards verified measurement results through traceable calibrations and checks.

Some primary laboratories operate reference methods such as Karl Fischer titration, but dissemination of measurement traceability to recognised primary references is far less fully implemented than in other fields of metrology. Certified reference materials (CRMs) for moisture exist, but only for limited values, sample sizes, and types of material.

These issues are being addressed in METefnet Metrology for moisture in materials (2013-2016) - a Joint Research Project (JRP) within the European Metrology Research Programme (EMRP). The project is designed to advance the state of the art by developing new and improved metrology, including:

- unambiguous realisation methods and new primary standards for water mass fraction

- improved measurement of water amount fraction using coulometric Karl Fischer titration

- new certified reference materials with traceability and improved stability

- novel transfer standards to enable dissemination of SI traceability with optimal accuracy

- methods for quantifying and reducing the effect of errors due to sample transport and handling

- a novel calibration facility with SI traceability for surface moisture meters

- methods for estimating uncertainty in selected industrial applications, that are both metrologically sound and practical

- more effective implementation of SI traceability in the field of moisture measurements

- steps towards a more coherent and developed moisture metrology infrastructure in Europe

The work focuses on selected materials, particularly pharmaceuticals, polymers and plastics, foodstuffs, animal feed, biomass, wood-based materials - but with applicability to a wider set of materials. New calibration, research and expert services and new CRMs are being developed for industry, science and the metrology community. Recommendations, reports and best practice guides will also be developed.

The work responds to needs identified in EURAMET ${ }^{b}$ roadmaps and strategy documents covering the moisture field [1-3]. The objectives were defined in the context of surveys to establish both user needs $[4,5]$ and the state of the art of top-level moisture metrology [3]. The JRP is a partnership of national metrology institutes (NMIs) and designated institutes (DIs) in Europe: NPL, CETIAT, CMI, DTI, INM INRiM, MIKES, TUBITAK UME, UL and UT, together with researchers at UNICLAM and UOULU. The project also involves a large group of collaborators comprising industrial stakeholders,

\footnotetext{
${ }^{b}$ The European Association of National Metrology Institutes
}

instrument companies, academics, and other NMIs worldwide. The core partners in the project bring together expertise from chemical metrology as well as physical metrology. These particularly include specialists in humidity metrology, which offers new scientific approaches to the moisture problems which are being explored in this work.

In all the sections that follow, "water content" refers to water specifically; "moisture content" refers to all liquids and volatiles (including water) relevant to the moisture measurement. The term "moisture" is also used for the combined area of both types of measurement with further qualification where necessary.

\section{Primary realisations and measurements}

\subsection{The issues for primary measurement}

In most moisture measurement applications, the "loss on drying" method (LoD) is recognised as the ultimate reference. There are many standardised variations of the method in use for different materials and applications. However, when drying a solid material sample, the measured mass loss does not depend only on the water content but also on the degree of binding of water and on the content of other volatile components in the sample. Therefore, the actual measurand in LoD measurements may significantly differ from the water mass fraction that may be assumed as the relevant SI quantity. Significant improvements need to be introduced to LoD-based measurement standards to remove this ambiguity in the primary measurement by this method. Furthermore, there is a need for uncertainty analysis methods for taking into account the variations in water binding and volatile contents in a sound way in the uncertainty budgets for primary realisations.

Alternatively, Karl Fischer titration methods are in use in the moisture measurement field as the reference for water amount fraction measurements in some application areas. These methods are primary because no reference in terms of moisture units is needed to obtain the water amount fraction value. Volumetric Karl Fischer titration method is less accurate than the preferred coulometric method (cKF). However, even for this the effect of completeness of water transfer and possible transfer of interferents in the measurement cell need to be studied. Research on volatiles and water binding related to sample heating is also relevant for "oven"-cKF used in cases when the sample material is insoluble in appropriate solvents.

Numerous published standards cover measurement methods or reference methods for moisture measurement. There are many standards because for each material or application a different protocol is recommended for temperature, sample handling, heating time, and end point determination. However there is variation in whether or how measurement traceability and uncertainty are addressed within documentary standards, and the use of such methods is often without recourse to any SItraceable verification of the results. Even when weighings 
are made with SI traceability, this does not guarantee that all of the water (or total moisture) has been extracted from the sample. Hence that is a potential weak link in the measurement traceability, and verification is desirable using suitable reference materials where they exist. Overall there is a need in the moisture field to reduce dependence solely on method-based standardisation of procedures, moving instead towards outcome-based verification of measurement results. This requires meaningful calibrations with traceability to the SI based on validated primary standards, and through use of reference materials, certified in terms of mass fraction or amount-of-substance fraction. To enable this, unambiguous but effective principles of SI traceability for moisture measurements must be established.

\subsection{Primary measurement solutions being developed}

\subsubsection{New gravimetric primary methods}

In order to strengthen the field of primary measurements of specifically water content, several primary methods are being developed. They combine traditional gravimetric approaches with water-specific detection using humidity measurements of various types to measure water vapour evolved from the sample and entrained in carrier gas (generally air).

DTI is applying a chilled-mirror based water vapour measurement traceable to primary dew point standards, with a specially designed sample cell for medium size samples (volume up to $\sim 200 \mathrm{~cm}^{3}$ ) particularly intended for foodstuffs, animal feed and fuel biomass. This cell is shown in Figure 1, and example data is illustrated in the graph in Figure 2.

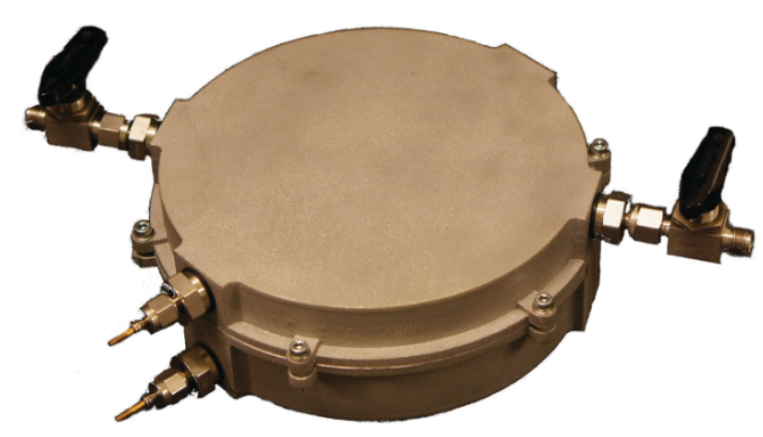

Figure 1. Photograph of the sample cell developed by DTI

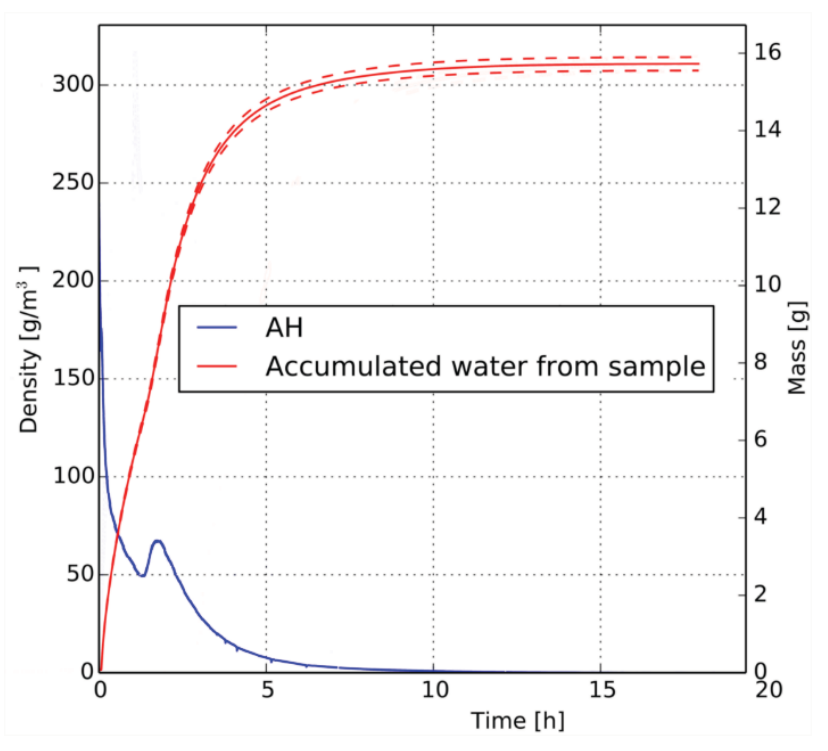

Figure 2. Graph illustrating the concentration of evolved water (falling curve), in grams per cubic metre of air, and the cumulative mass of water detected (rising curve), in grams.

NPL is applying electrolytic water vapour measurement as the water loss detection and developing a primary standard. This uses an adapted commercial instrument (Sartorius Model WDS 400), validating it from first principles with traceability items of current. This is suitable for small samples (from milligrams to of order 2 grams) typically in form of powder, small pellets or film. In addition, CETIAT and INRiM are also working with effectively the same instrument model identified as Berghof EasyH2O.

MIKES is applying water vapour detection using a combination of a capacitive humidity sensor with a condensing water trap, particularly targeting biomass and wood at various particle and sample sizes [6].

INM and TUBITAK UME are applying a combination of Karl Fischer titration and thermogravimetric analysis, to measure paper and plastic film, studying how the degree of binding of water can be distinguished.

For all the newly developed methods, rigorous validation and estimation of uncertainty is essential for them to be considered as primary methods usable to provide SI traceability for measurements of water content. In addition, each new method is being compared against documentary standard methods relevant to the material concerned, to study the level of agreement with established approaches. This is vital for the acceptance of the new approach across various fields of industry.

A trial intercomparison has been made between the newly developed methods measuring fuel wood pellets, and further comparisons using other materials will follow. The comparison results will be used for probing the general validity of the findings and for informing the design of future comparisons at more formal levels such as key comparison under the International Committee for Weights and Measures (CIPM) or regional metrology organisations (RMOs). 


\subsubsection{Improved Karl Fischer titration methods}

UT and INM are carrying out an in-depth metrological study of the coulometric Karl Fischer titration method (cKF) with the aim of proposing improvements for reducing its uncertainty when applied to measurements of moisture in solid samples. This will address the different uncertainties in the case of different materials, and will provide rigorous uncertainty estimates (in contrast to the limited uncertainty information often available). The reduction of uncertainty will be achieved by optimising the parameters of the KF titrator itself (stirring speed, background correction, endpoint determination, etc.) as well as the sample oven (sample size, sampling temperature, carrier gas flow rate, etc.). Results are emerging that may provide a new and more accurate way of determining the endpoint of a titration process.

\section{Traceability and dissemination}

\subsection{The measurement traceability issues for moisture}

In principle classical measurements of mass loss on drying benefit from SI traceability to mass, and Karl Fischer Titration measurements can have electrical traceability to current. However there is risk of error if not all the analyte is extracted, or if the wrong measurand is assumed (either water, or all moisture including other liquids or volatiles). Because of this, traceable reference materials are important either as the route of measurement traceability, or for verification of results. Figure 3 illustrates possible routes for measurement traceability.

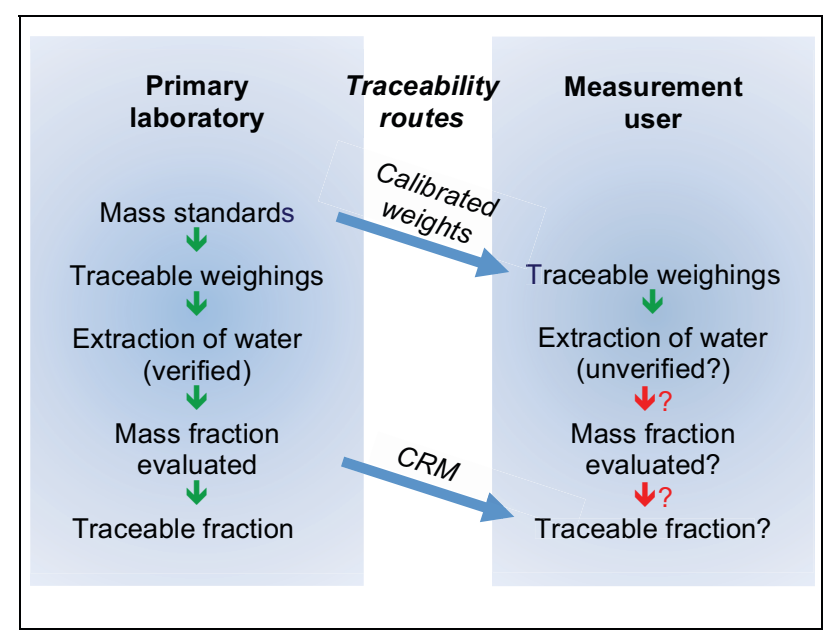

Figure 3. Diagram showing different routes of measurement traceability. CRMs can provide traceability or can underpin steps that users may not otherwise be able to verify.
However, few certified and standard reference materials are available for moisture, or water content specifically. Reference materials are usually matrix- (material-) specific, and considered to have limited wider applicability. Typically CRMs for water specifically or moisture generally are not available in the variety of ranges, formats, sample sizes, and matrix materials to meet the needs of many users and instrument types. Water is often an important component of CRMs certified for different aspects of composition, but water content in these cases is rarely certified (indicative). Where waterspecific CRMs exist, frequently the certified values have been assigned by consensus, possibly without rigorous SI traceability or best practice in uncertainty evaluation [7, 8]. Overall, there is a strong need for a wider variety of moisture CRMs with traceability to the SI, improved metrological properties and recognised certification. These are essential in providing traceable realisation of moisture fraction. This can reduce dependence of users on method-based implementation of methods, for which traceability to mass alone is not enough to assure correct and traceable measurement results.

In disseminating traceability or carrying out interlaboratory comparisons, use of a transfer standard instrument instead of reference materials is also a valuable approach. For these, there is particularly a need to ensure that the state of binding is understood for a particular measurement (considering whether "free" "capillary" or "bound" water is effectively measured).

Samples taken directly from a manufacturing process also have an important role in measurement traceability. In many cases, however, the results are distorted by moisture exchange between the sample and its surroundings during handling and transportation. Developments are needed to reduce the errors that handling can cause, and to estimate the total uncertainty of the result value relevant to the process.

Several practical moisture techniques (using resistive, capacitive, microwave and near infrared sensing) are used for measuring surface moisture of materials to a given depth. However there can be significant moisture gradients close to the surface, and calibration cannot be based on a simple value of bulk moisture content. The effects of moisture gradients need to be studied so that calibration procedures can be developed that take this into account.

\subsection{Solutions being developed for moisture traceability}

\subsubsection{New certified reference materials}


New candidate CRMs are being studied for certification with SI traceability. Shortlisted materials are selected to improve on existing available range, stability and relevance for different measurement techniques. NPL, UT and INM are studying the candidate materials including intercomparisons and uncertainty analysis as a requisite for one or more for to be qualified as a CRM. The study includes trials with different instrument types such as microwave resonator, and bench-top integrated "thermal balances" which are widely used. Desirable properties are long-term stability of calibrated value, and availability in large sample sizes. To meet these requirements, a selection of chemical salts are being evaluated, with promising initial results.

\subsubsection{Improved sample handling and transportation}

In order to quantify and reduce the measurement errors and uncertainty due to moisture changes in samples during transportation several approaches are being trialled by MIKES, CMI, INM, INRIM, and TUBITAK UME. These include: experimenting with continuous ambient monitoring for the sample transportation, studying experimentally the effects of various parameters on samples relevant to transportation, developing analysis methods for estimating the uncertainty, and exploring possibilities to introduce a correction factor for error due to the moisture changes. The study is considering the effects of ambient temperature and humidity, exposure time, packaging materials and package closures. The work includes development of specialised sample holders for strongly hygroscopic samples. Based on the conclusions; a guide to good practice for transportation of moist samples will be produced, with appropriate links to existing guidance documents for sampling.

\subsubsection{New transfer standards}

CETIAT, INRIM, and TUBITAK UME are developing improved methods and equipment for the transfer standard based dissemination of SI traceability. One aspect is the development of a non-invasive and nondestructive transfer standard based on radio-frequency wave and microwave at a low energy level for direct determination of moisture. Operation in a range of wavelengths is intended to allow water in different phases and levels of binding to be distinguished. Secondly, a low-cost, portable system is being developed, comprising a microwave moisture meter and a system for maintaining an internal reference in very stable conditions. Due to the versatility with respect to the internal reference and the microwave measurement, the system will be applicable to a wide range of materials and applications. Figure 4 shows the capacitive cell designed by CETIAT for measuring solid and liquid samples.

\subsubsection{Novel calibration methods for surface moisture sensors}

UL, CMI and TUBITAK UME are developing traceable calibration methods for surface moisture sensors A

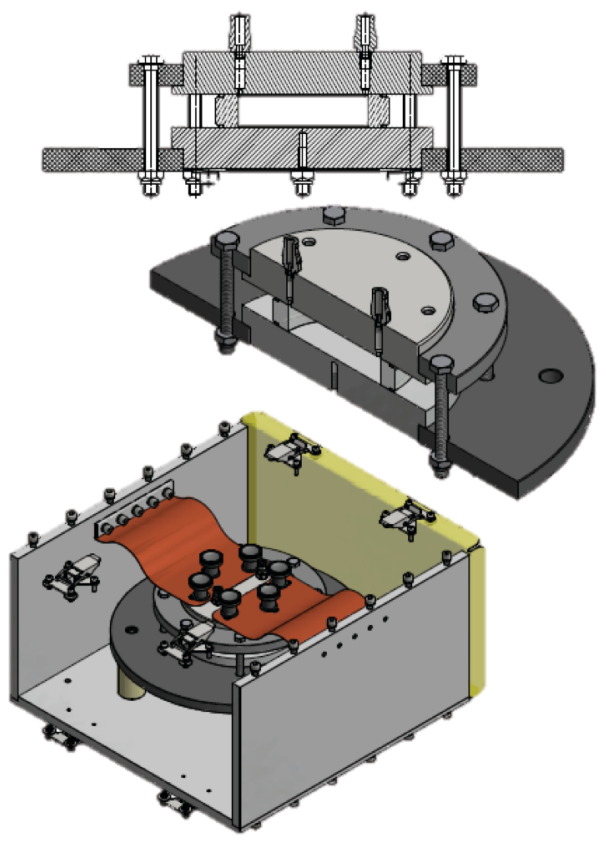

Figure 4. Capacitive cell designed for measuring water content of solid and liquid samples

facility is being constructed by UL to realise a controlled moisture gradient in a specimen. A prototype form of the facility is shown in Figure 5. Air of controlled humidity at two different values on either side of a sample is used to establish a moisture gradient in a material. In addition, studies have been made using laminar structures assembled from layers of different moisture content. In this way, tests have been made of instrument ability to distinguish surface and subsurface layers of moisture [9].

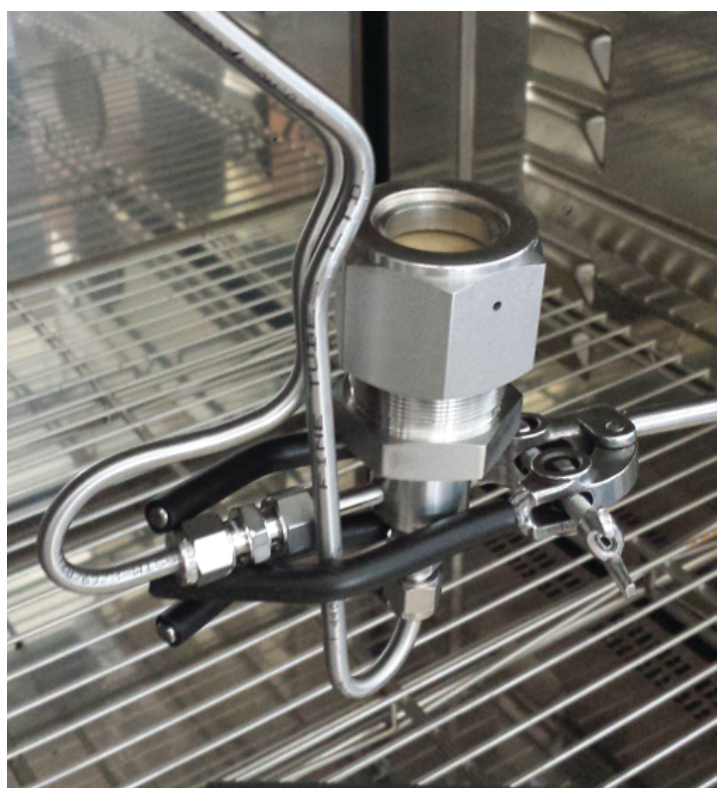

Figure 5. Prototype system for generating moisture gradient in a sample, for calibration of surface moisture sensors. 


\section{Metrological underpinning modelling and uncertainty analysis}

\subsection{The needs}

Many processes involving water in materials are not well understood. Often, a measurement or realisation can only address a bulk property, or perhaps only a boundary condition (at a material surface). In such cases there is a need for insight into aspects such as, moisture profile, moisture transport, and surface interactions with air and water vapour.

The physics of moisture in materials involves highly non-linear processes of combined mass and energy transfer with phase transitions within porous media. To extend knowledge of these processes requires development of suitable detailed mathematical descriptions of both free-fluid and porous regions in nonstationary conditions, to yield information about moisture distribution.

The other key area of modelling for moisture is the analysis of uncertainty. In moisture measurements, this needs to address not only instrumental factors, but also variables such as sample collection, handling, transport, and storage. Tools are required to support users in correctly identifying and quantifying sources of uncertainty for these aspects of moisture measurements.

\subsection{Solutions being developed}

\subsubsection{Moisture modelling}

Mathematical models are being developed by INRIM, CMI, DTI, TUBITAK, and UNICLAM $[10,11]$ to evaluate combined mass and energy transfer with phase transitions within porous media. The model conditions are defined in terms of binding energy relating to levels such as: free or surface water, physically-bound porous or capillary water, physico-chemically absorbed water, and chemically-bound water. These properties together with temperature, pressure, velocity and species concentration, can allow evaluations of moisture profile and transport.

This modelling work is designed to underpin new traceability mechanisms and to improve the applicability of existing SI traceability mechanisms for moisture. The work is addressing both steady-state and transient regimes. The models will be experimentally validated in selected cases. This will support a fundamental understanding of the physical processes during moisture transport in selected materials as well as contributing to the effective definition of the measurand, and to a better understanding of the measurement uncertainty. Such models can provide a "virtual laboratory" to assist in solving numerous problems. Potential areas of use are the design of moisture control system (e.g. in drying processes), in the determination of the optimal moisture conditions for a given material (e.g. in CRM development and storage), and in the investigation of the interaction between moist samples and moisture content
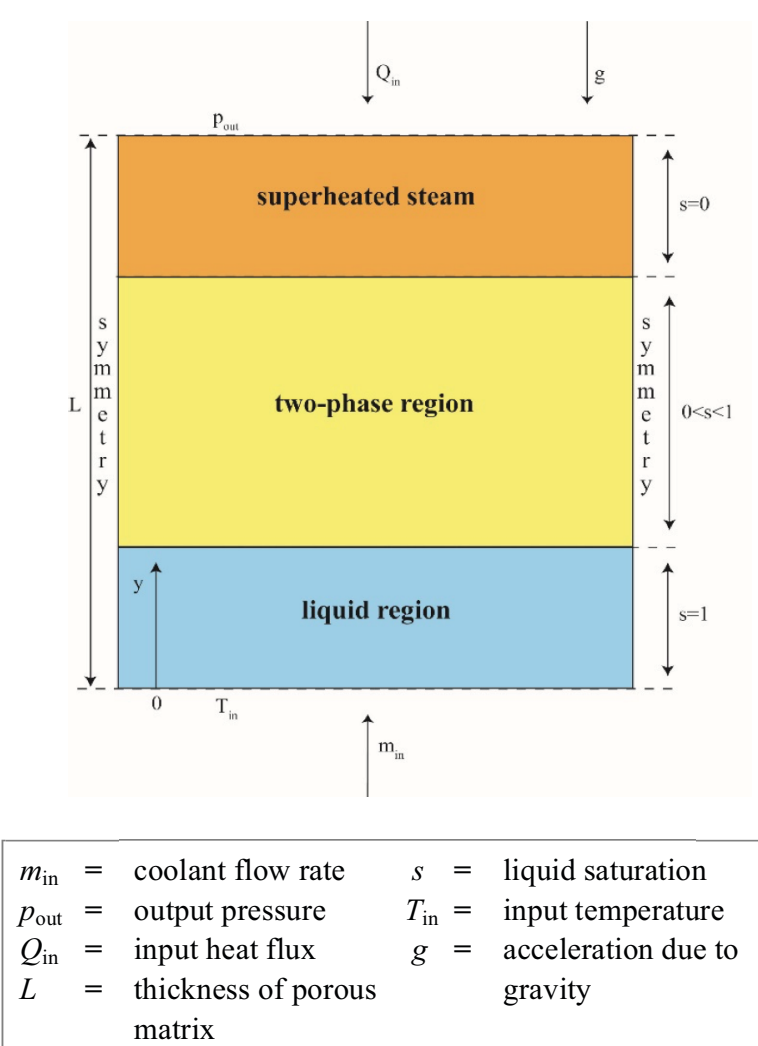

Figure 6. Physical model of transpiration cooling with phase change in a porous medium as a function of thickness, coolant mass flow rate temperature and applied heat flux

measurement methods (e.g. for instrumentation development).

Example outputs of the modelling work are shown in the following figures. Figure 6 illustrates a physical model of transpiration cooling with phase change in a porous medium. Figure 7 shows a graphical view of saturation variation as a function of the sample thickness, and Figure 8 shows a 3-D visualisation of a numerical simulation of water removal in a polymer sample.

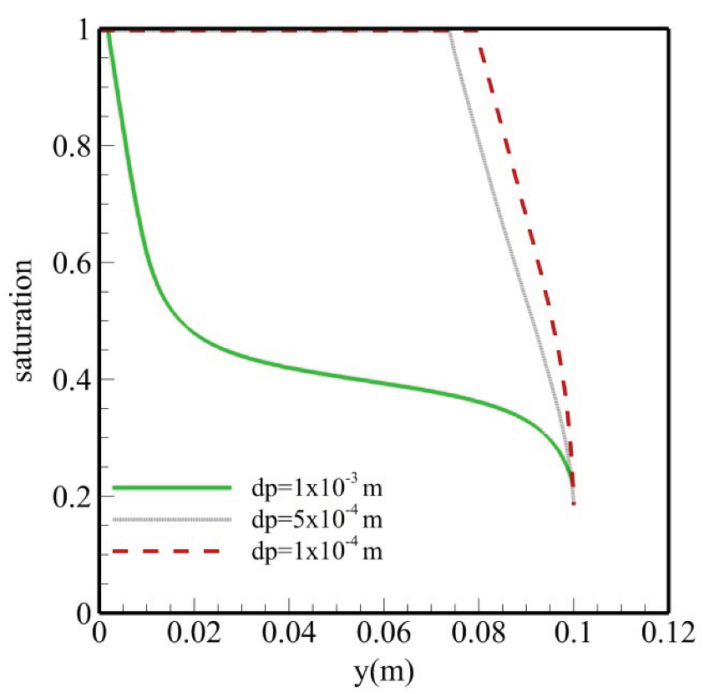

Figure 7. Graph of results from physical model of transpiration 


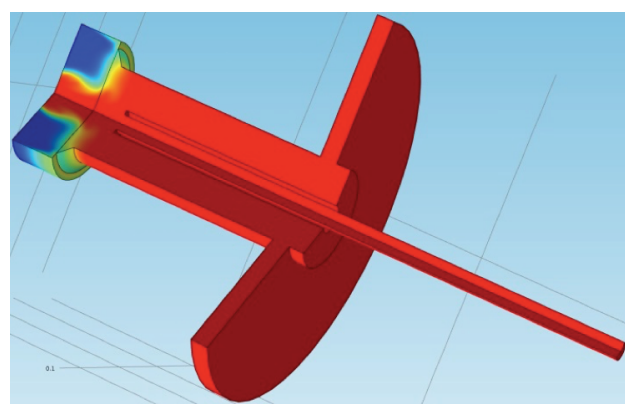

Figure 8. Visualisation of numerical simulation of water removal in a sample of polyamide 66. Dry air flows (from right) through the small diameter tube towards the disk shaped sample (top left) causing a variation of the initial water content.

\subsubsection{Development of uncertainty models}

TUBITAK, INM, INRIM, UT and UNICLAM are developing uncertainty analyses of moisture measurements, linking closely with the outputs of the other areas of the project. The analysis will use information from both the mathematical models and the practical studies throughout the project, in order to build up comprehensive model uncertainty budgets. These will be applicable to practical cases of interest for accredited testing and calibration laboratories and accreditation bodies and others. The outputs will be in the form of spreadsheet-based templates, together with guidance for evaluation. This will address the measurements themselves and also uncertainties due to sampling, sample handling, transport and storage. In addition to bulk moisture, the analyses will make steps towards addressing moisture profile. The uncertainty models will provide a valuable tool for optimising the quality of measurements and for underpinning measurement best practices in testing and calibration laboratories as well as in industrial process applications.

\section{Metrology infrastructure}

\subsection{Current metrology infrastructure}

As for any field of measurement, moisture metrology needs a framework of recognised routes for defining quantities, scales and units of measurement, for measurement traceability and for international harmonisation. Ideally the infrastructure includes provisions at $\mathrm{BIPM}^{\mathrm{c}}$ consultative committee level, and in regional metrology organisations, allowing for BIPM Calibration and Measurement Capabilities (CMCs) and key comparisons to be established. These would support national dissemination of traceability, recognised accreditation of laboratories, and ultimately widereaching measurement traceability. For the moisture field, elements of this infrastructure are not in place or not coherently addressed. Moisture interests span physical

\footnotetext{
${ }^{\mathrm{c}}$ International Bureau of Weights and Measures
}

and chemical metrology, and there are multiple routes of traceability; in terms of mass, electrical quantities, composition (via reference materials) or to temperature via humidity measurements as in this project. Hence treatment of the subject has been fragmented to date. It is known that the regional metrology organisation COOMET $^{\mathrm{d}}$ has reviewed CMCs for $\mathrm{UNIIM}^{\mathrm{e}}$ for moisture in grain and in milk (for both measurements and reference materials). However, there is some debate as to whether moisture as a "method-defined" measurand can be the subject of a BIPM CMC. Further discussions of this essential question are planned during the time frame of the project.

Published standards can be considered a key part of metrology infrastructure in the moisture field, since there is extensive use of standardised methods. It is widely assumed that standardising a method leads to a consistent and correct outcome. However there is a need for outcome-based verification using methods and certified materials providing values traceable to the SI, with valid and realistic uncertainties. Therefore, interaction with developers and users of moisture-related standards is essential for disseminating best practice for this.

Legal metrology has its metrology infrastructure under the International Organization for Legal Metrology. This is particularly relevant to grain moisture, for which there are well established methodologies for traceable measurements.

\subsection{Proposed developments for metrology infrastructure}

For new approaches to measurement traceability to be successful, there needs to be a clear metrological framework. Steps are being taken to develop and strengthen the metrology infrastructure in the moisture field. Presentations have been made to metrology committees such as working groups or plenary meetings of the CIPM CCT ${ }^{\mathrm{f}}$ and $\mathrm{CCQM}^{\mathrm{g}}$, and of EURAMET Technical Committees for Thermometry and Chemistry. A discussion document was submitted to the 2015 meeting of the CCQM Inorganic Analysis Working Group, setting out ideas about how moisture or water content could be addressed in a CMC. Further interaction on this will continue during the course of the project, and with intent for lasting cooperation between the CCT and CCQM in this subject.

To support all this, a review of metrology vocabulary relevant to moisture is underway in the project, drawing on existing vocabulary in chemistry metrology [12]. This is in order to underpin clear cross-disciplinary understanding of fundamental issues such as defining the measurand. Stemming from the understanding gained in the development of the primary measurements throughout

\footnotetext{
${ }^{d}$ The Euro-Asian Cooperation of National Metrological Institutions

${ }^{\mathrm{e}}$ Ural Scientific Research Institute of Metrology

${ }^{f}$ Consultative Committee for Thermometry

${ }^{g}$ Consultative Committee for Amount of Substance:

Metrology in Chemistry and Biology
} 
the project, recommendations will be made for the principles of SI traceability for moisture content and

Table 1. List of relevant standardisation committee interactions during early stages of the EMRP METefnet work

\begin{tabular}{|l|l|}
\hline $\begin{array}{l}\text { Committee } \\
\text { identification }\end{array}$ & Title \\
\hline CEN/TC 335 & Biofuels \\
\hline CEN/TC 346 & Conservation of Cultural Heritage \\
\hline BSI AW/4 & Cereals and pulses \\
\hline BSI CII/37 & Fertilisers and related chemicals \\
\hline BSI AW/8 & Tea \\
\hline BSI PRI/82 & Thermoplastic materials \\
\hline BSI NFE/36 & $\begin{array}{l}\text { Copper lead and zinc ores and } \\
\text { concentrates }\end{array}$ \\
\hline BSI PTI/16 & Solid mineral fuels \\
\hline
\end{tabular}

specifically water content. By the end of the project, a proposal will be drafted for how metrology infrastructure can be further developed for the moisture field. The project participants are also interacting with relevant standardisation committees. Project partners will progressively promote the inclusion in documentary standards of traceable calibration methodology, and best practices in evaluating and reporting measurement uncertainty. Doing so has great potential to impact endusers of moisture measurements across many and varied sectors. Table 1 shows the standardisation committees involved so far, and there are plans to approach a number of others during and beyond the time frame of the project.

\section{Dissemination of outputs}

Benefits of the project are being realised through dissemination of the technical outcomes to stakeholders at all levels in the moisture field. Knowledge transfer activities include liaison with stakeholders in group activities and individually (through meetings, visits, correspondence, and though collaborative inputs into technical tasks). The project is progressively generating scientific presentations and publications, user-friendly good-practice guides, and an expansion of contacts into relevant standardisation committees.

New training material is being developed covering best practice in moisture metrology, measurement traceability, and uncertainty. This material will be available to all project partners to adapt for delivery at any level from NMI scientists to industrial end-users of measurements, translated into local languages if required.

Exploitation of the project outputs will include the provision of new or improved measurement services or consultancies to customers, on commercial terms, by most of the project partners.

The project is also engaging with a number of national user interest groups such as National Kelvin Club (Finland), and the UK Reference Materials Working Group.

The METefnet project maintains a website [13], where details of the technical work are given, and outputs of the project are progressively being made available for download.

\section{Acknowledgements}

This work was funded by the Joint Research Project SIB64 METefnet of the EMRP, and co-funded through the NMIs and DIs of the authors. The EMRP is jointly funded by the EMRP participating countries within EURAMET and the European Union.

\section{References}

1. S. Bell, R. Benyon, N. Böse and M. Heinonen. TEMPMEKO 2007. Int. J. Thermophys. 29, Number 5 / October, 2008, Pages 1537-1543

2. V. Fernicola, S. Bell, R. Benyon, N. Böse, E. Georgin, M. Heinonen, D. Hudoklin and M. Sargent, Int. J. Thermophys. (to be published)

3. S. Bell, N. Boese, R. Bosma, M Buzoianu, P Carroll, V Fernicola, E Georgin, M Heinonen, A Kentved, C Melvad and J Nielsen, Int. J. Thermophys. DOI 10.1007/s10765-015-1859-6, 2015

4. P. A. Carroll, S. A. Bell and M. Stevens Calibration issues for measurement of moisture in materials, NPL Report ENG 21, January 2010, ISSN 17542987

5. P. A. Carroll, S. A. Bell, Consultation on the use of certified reference materials for the calibration of moisture measurement instrumentation NPL Report ENG 40, 2012

6. M. Ojanen, H. Sairanen, K. Riski, H. Kajastie, M. Heinonen, J. Meas. Sci., 9 (2014), No. 4, pp. 56-60

7. BIPM, IEC, ILAC IFCC, IUPAP IUPAC, and OIML ISO. "Evaluation of measurement data-guide for the expression of uncertainty in measurement. JCGM 100: 2008." (2008).

8. S L R Ellison and A Williams (Eds). Eurachem/CITAC guide: Quantifying Uncertainty in Analytical Measurement, Third edition, (2012).

9. S. Beguš, G. Begeš, J. Drnovšek and D. Hudoklin, Sensors and Actuators A: Physical 221 (2015): 53-59

10. F. Arpino, G. Cortellessa, M. Dell'Isola, N. Massarotti and A. Mauro, Numerical Heat Transfer, Part A: Applications, 64, Issue 8, pages 839-862, (2014)

11. F. Arpino, G. Cortellessa, A. Mauro, Numerical Heat Transfer, Part A: Applications (to be published)

12. V. J. Barwick and E. Prichard (Eds), Eurachem Guide: Terminology in Analytical Measurement: Introduction to VIM 3 (2011).

13. www.metef.net (accessed 6 July 2015)

(C) Queen's Printer and Controller of HMSO, 2015. 